\title{
Corrosion Inhibition of Aluminium Pigments in Aqueous Alkaline Medium Using Plant Extracts
}

\author{
Chris O. Akalezi ${ }^{1}$, Cynthia E. Ogukwe ${ }^{1}$, Conrad K. Enenebaku ${ }^{1}$ \& Emeka E. Oguzie ${ }^{1}$ \\ ${ }^{1}$ Electrochemistry and Materials Science Research Laboratory, Department of Chemistry, Federal University of \\ Technology, Owerri, Imo State, Nigeria \\ Correspondence: Chris O. Akalezi, Electrochemistry and Materials Science Research Laboratory, Department of \\ Chemistry, Federal University of Technology, PMB 1526 Owerri, Imo State, Nigeria. Tel: 234-808-058-7128. \\ E-mail: chrisakalezi@ yahoo.com
}

Received: September 21, 2011 Accepted: October 11, 2011 Online Published: June 13, 2012

doi:10.5539/ep.v1n2p45 URL: http://dx.doi.org/10.5539/ep.v1n2p45

\begin{abstract}
This work examines the efficacy and efficiency of Bucolzia coriacea (BC) and Cninodoscolus chayansa (CC) plants extracts as corrosion inhibitors for aluminium pigments using gas volumetric technique. The results obtained from this study indicate that all the extracts inhibited the corrosion process by extending the latency periods of the aluminium pigment-extract mix far beyond that of the bare aluminium pigment. Inhibition efficiency obtained was not only concentration dependent but also plant dependent and followed the order: $\mathrm{BC}>\mathrm{CC}$. A linear correlation was obtained between inhibition efficiency and duration of latency for each extract. Molecular modeling was used to evaluate the structure, electronic reactive parameters of the plant extracts in relation to their effectiveness as corrosion inhibitors.
\end{abstract}

Keywords: Aluminium pigments, corrosion, inhibitors, alkaline medium

\section{Introduction}

Metallic pigments are being increasingly used in various kinds of applications. As one of the important metallic pigments, aluminium particles have been widely used in printing inks, automobiles, roofing and painting industries for many years because of its shiny appearance, excellent properties and cheap price (Kiechl, 1999; Lui et al., 2007; Karlson, 2006). Aluminium pigments are usually manufactured from aluminium granules by a ball milling process in the presence of mineral spirit and fatty acid (Karlson, 2006). During the process of forming, the surface areas of the aluminium particles are drastically increased, resulting in high surface reactivity by water (Reisser et al., 1995; Karlson, 2006; Kiechl, 1999; Muller, 1995a).

Due to increasing environmental awareness and the need to replace solvent-borne coatings, water borne paints and inks are nowadays being developed as environmentally friendly alternatives. For coatings based on aluminium pigments, replacing the organic solvent by water however poses a considerable challenge. This is because under the slightly alkaline conditions in which most water-borne paints exist, aluminium reacts with water to form aluminium oxide and aluminium hydroxide according to the scheme (Karlson, 2006; Lui et al., 2007; Kiehl et al., 1999; Muller et al., 2001a; Muller, 2004):

$$
\begin{array}{r}
2 \mathrm{Al}+3 \mathrm{H}_{2} \mathrm{O} \rightarrow \mathrm{Al}_{2} \mathrm{O}_{3(\mathrm{~s})}+3 \mathrm{H}_{2} \\
2 \mathrm{Al}+6 \mathrm{H}_{2} \mathrm{O} \rightarrow 2 \mathrm{Al}(\mathrm{OH})_{3(\mathrm{~s})}+3 \mathrm{H}_{2}
\end{array}
$$

These reactions lead to loss of the shiny appearance of the pigment particles and more importantly the evolved hydrogen gas may lead to unacceptable pressure build up in containers and constitute explosion hazards (Muller, 1999; Muller et al., 2001b; Besold et al., 1995). Hence there is a need to protect the surface of pigment particles using suitable corrosion inhibitors, which show sufficient affinity for the pigment surface. Again, owing to increasing ecological awareness and strict environmental regulations as well as the inevitable drive towards sustainable and environmentally friendly processes, attention is now focused on the development of substitute nontoxic alternatives to inorganic and organic inhibitors applied earlier. Consequently the current focus in corrosion inhibitor research is to identify and develop new classes of non toxic, benign, inexpensive and efficient alternatives. In this regard, there has been increasing interest in investigating natural products of plant origin for 
corrosion inhibiting efficacy.

Abdel-Gaber et al. (2008) investigated the inhibition of aluminium corrosion in alkaline solutions using Ambrosia maritime L (damsissa) extract employing different chemical and electrochemical techniques. Water extracts from leaves of date palms, phoenix dactylifera, henna, Lawsonia inermis, and corn (Zea mays), were tested as corrosion inhibitors for steel, aluminium, copper and brass in acids and sodium hydroxide solutions, using weight loss, solution analysis and potential measurements (Rehann et al., 2003). Priya et al. (2005) studied the corrosion behaviour of aluminium in rain water containing garlic extract. The inhibitive action of the acid extracts of seeds, leaves and barks from the Ficus virens plants towards hydrochloric and sulphuric acid corrosion of aluminium has been tested using weight loss and thermometric techniques (Jain et al., 2006). Kliskic et al. (2000) analyzed aqueous extract of Rosmarinus officiantus as corrosion inhibitor for aluminium alloy corrosion in chloride solution. EL-Hosary et al. (1972) studied the corrosion inhibition of aluminium and zinc in $\mathrm{HCl}$ using Hisbiscus subdariffa extract. Avwiri and coworkers (2003) studied the inhibitive action of Vernonia amygdalina on the corrosion of aluminium alloy in $\mathrm{HCl}$ and $\mathrm{H}_{2} \mathrm{SO}_{4}$. A series of reports from our laboratory investigated the corrosion inhibition efficiency of some plant extracts including Sansevieria trifasciata, Ocimum basilicum, Telfaria occidentalis extracts on aluminium and mild steel corrosion in different environments using the gas volumetric technique (Oguzie et al., 2005; Oguzie, 2005 \& 2007). The studies revealed that the gasometric technique was well suited for the present investigation

Unlike aluminium metal, corrosion and corrosion inhibition of aluminium pigments has not attracted so much attention and such studies are not widely reported. Nevertheless, the few studies in the area have demonstrated that the same theories and mechanisms apply and some organic compounds that inhibit aluminium metal corrosion also function well on aluminium pigments. The organic inhibiting agents range from low molecular weight substances such as phenols and aromatic acids; surfactants such as alkyl phosphates and other anionic amphiphiles, to high molecular weight compounds such as polyelectrolyte (Karlsson et al., 2006; Das et al., 2004; Kummert et al., 1980; Muller et al., 2001b, 2002 \& 2003; Muller, 2000; Muller, 1995b). A common feature for them all is that they contain functional groups that interact specifically with aluminium at the surface by adsorption and plant extracts are rich in such species. Interestingly, recent developments in DFT-based quantum chemical computations have intensified the search for new and more efficient inhibitors. Quantum chemical methods and molecular modeling techniques enable the definition of a large number of molecular quantities characterizing the reactivity, shape, and binding properties of a complete molecule as well as of molecular fragments and substituents. These are, namely, the geometrical structure of the molecule, the dipole moment, the highest occupied molecular orbital (HOMO) energies and lowest unoccupied molecular orbital (LUMO) energies (Matinez et al., 2003; Gece, 2008; Levine, 1991).

The present study investigates the efficacy and efficiency of plant extracts as corrosion inhibitors for aluminium pigments in aqueous alkaline environments using the gas volumetric technique. Two different plant extracts: Cninodosculu chayansa (CC) and Buchulzia coriacea (BC) have been evaluated for their effectiveness in controlling the corrosion of aluminium pigment in aqueous alkaline environment at varying conditions of temperature, $\mathrm{pH}$ and concentration. Attempt has also been made to determine the molecular electronic structures of some of the extract components by means of quantum chemical calculations in the framework of the density functional theory (DFT). This is to enable elucidation of the possible adsorption sites in the molecules.

\section{Experimental}

\subsection{Material}

$100 \%$ unstabilized nonleafing aluminum pigment powder (average particle diameter $16 \mu \mathrm{m}$; specific surface about $5 \mathrm{~m} 2 / \mathrm{g}$ : BET method) was used. The corrosion medium consists of a mixture of $100 \mathrm{~mL}$ of water and buthyl glycol in the ratio 9:1. To improve the wetting of the hydrophobic aluminium particles, $2.0 \%$ a wetting agent (adduct of 10 moles of ethylene oxide to nonylphenol) was added. The $\mathrm{pH}$ value of the medium was raised to 10.5 and sometimes to 8.5 with triaminomethylphenol (AMP3). All reagents were supplied by Benda Lutz of Austria.

Stock solutions of the biomass extracts were prepared by boiling weighed amounts of the dried and ground leaves of $\mathrm{CC}$ and $\mathrm{BC}$ under reflux for $3 \mathrm{~h}$ in $0.5 \mathrm{M} \mathrm{NaOH}$. The resulting solutions were allowed to cool to room temperature and filtered. The amount of plant material extracted into solution was quantified by comparing the weight of the dried residue with the initial weight of the powdered plant material before extraction. Inhibitor test solutions were prepared from the respective stock solutions by appropriately diluting with $\mathrm{NaOH}$. 


\subsection{The Gasometry}

The gasometric assembly is essentially an apparatus that measures the volume of gas evolved from a reaction system and consist of a $250 \mathrm{ml}$ Erlenmeyer flask connected via a delivery tube to a burette which was in turn connected to a reservoir of paraffin oil. This set-up provides a rapid and sensitive means for gauging any perturbation by an inhibitor with regard to gas evolution within the system. Results obtained by this technique are well corroborated by other well established techniques including weight loss thermometric, potentiostatic polarization and impedance spectroscopy amongst others.

\subsection{Experimental Procedure}

$1 \mathrm{~g}$ of the aluminium pigment was weighed and placed into a $250 \mathrm{ml}$ Erlenmeyer flask. $100 \mathrm{ml}$ of the test solution was added to the Erlenmeyer flask, and the magnetic stirring bar. The $\mathrm{pH}$ value was checked and readjusted with AMP3.

The magnetic stirrer was switched on and the thermostat set to the required temperature. The liquid level in the burette was adjusted to zero level and the valves opened. The temperature was allowed to balance for 10 minutes. The generation of gas volume was read periodically and the test was concluded after generation $100 \mathrm{ml}$ of hydrogen.

During the inhibition test the plant extracts were dissolved (in vol. concentrations) in the corrosion medium before the dispersion of the aluminium pigment, and the $\mathrm{pH}$ adjusted as necessary. The settled aluminium pigment showed initially a metallic sparkle and reacted completely by rapid effervescence resulting from hydrogen gas evolution to form aluminium hydroxide.

\section{Results and Discussion}

\subsection{The Aluminium Pigments}

The progress of the corrosion reaction of the standard aluminium pigments were assessed by measuring the volume of hydrogen gas evolved with time. Figure 1 represents the data obtained during the corrosion of standard aluminium pigment in the test solution at $\mathrm{pH} 8.5$ and 10.5 and temperatures 30 and $40^{\circ} \mathrm{C}$. A close inspection of the data reveals not only the presence of a period in which there were no gas evolution but also a difference in the values obtained at $\mathrm{pH} 8.5$ and that at $\mathrm{pH} 10.5$. This period has been referred to by various names such as induction period or incubation period (Oguzie, 2008) or latency period (Muller, 1999) and represents the time required by the solution to neutralize the pre-immersion oxide coating on the aluminium pigment surface.
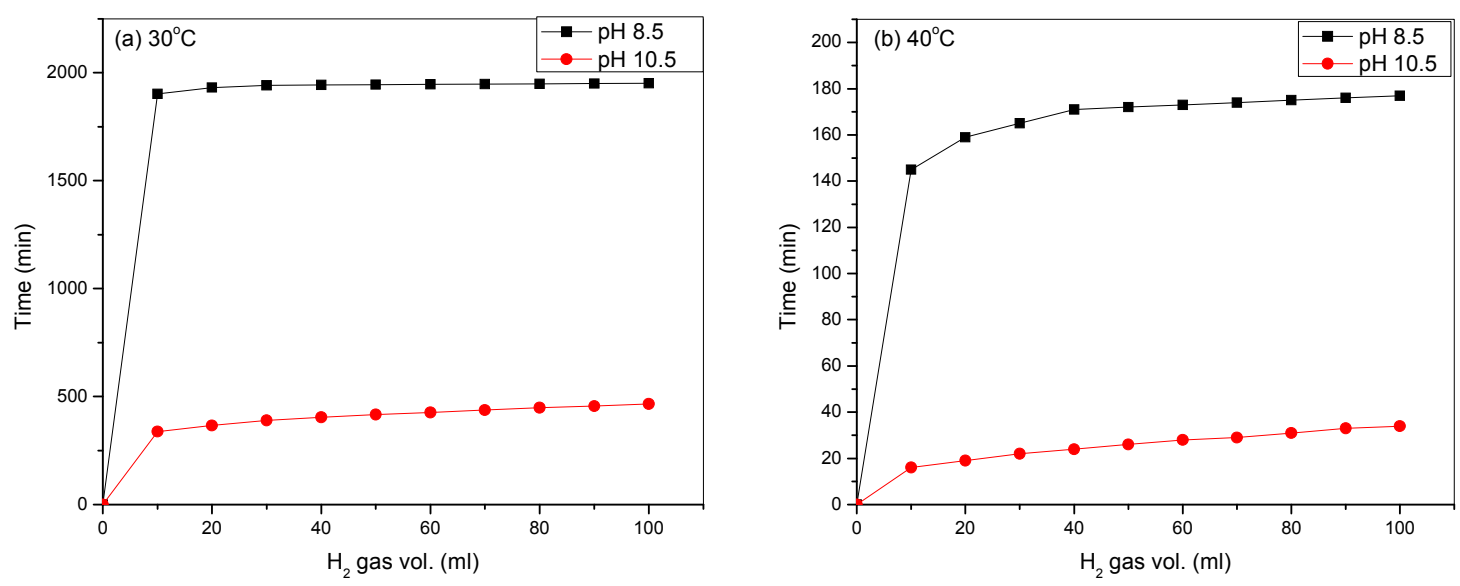

Figure1. Plots of the hydrogen gas evolution during the corrosion of standard aluminium pigment in alkaline medium at (a) $30^{\circ} \mathrm{C}$ and (b) $40^{\circ} \mathrm{C}$. Corrosivity of an environment corresponds to the time interval required to generate $100 \mathrm{ml}$ of $\mathrm{H}_{2}$ gas

Other authors (Muller, 1999, 2004) had obtained similar pH-dependencies in the latency periods using similar techniques and other corrosion inhibitors for aluminium and this effect was attributed to the influence of isoelectric point (IEP) $\mathrm{pH}$ of aluminium ( $\mathrm{pH}$ 9) (Harman, 1994). At $\mathrm{pH} 8$ (below the (IEP)) the aluminium surface is positively charged, whereas at $\mathrm{pH} 10$ (above the (IEP)) the surface is negatively charged and here we are considering an aqueous solution containing other ions. The preponderance of negatively charged ions can lead to instability in the system resulting from charge repulsions. 
The stability of the aluminium surface as a function of $\mathrm{pH}$ can also be derived from the Pourbaix diagram (Harman, 1994). At very low potential we have the immunity regions of aluminium meaning that aluminium will not react. At low $\mathrm{pH}$ values $\mathrm{Al}$ is not stable in aqueous solutions and the formation of $\mathrm{Al}$-ions will take place, also at high $\mathrm{pH}$ values aluminate anions are formed. Between $\mathrm{pH} 4$ and 8.5 the oxide layer is stable.

Figure 2 compares the latency period obtained at $\mathrm{pH} 8.5$ with that obtained at $\mathrm{pH} 10.5$ at $30^{\circ} \mathrm{C}$ and $40^{\circ} \mathrm{C}$. Same plot also compares values at $\mathrm{pH} 8.5$ with $\mathrm{pH} 8.5$ and $\mathrm{pH} 10.5$ with $\mathrm{pH} 10.5$ at the different temperatures. The lower latency periods at $\mathrm{pH} 10$ at the higher temperature is indicative of the higher corrosion susceptibility of aluminium pigment at higher temperature.

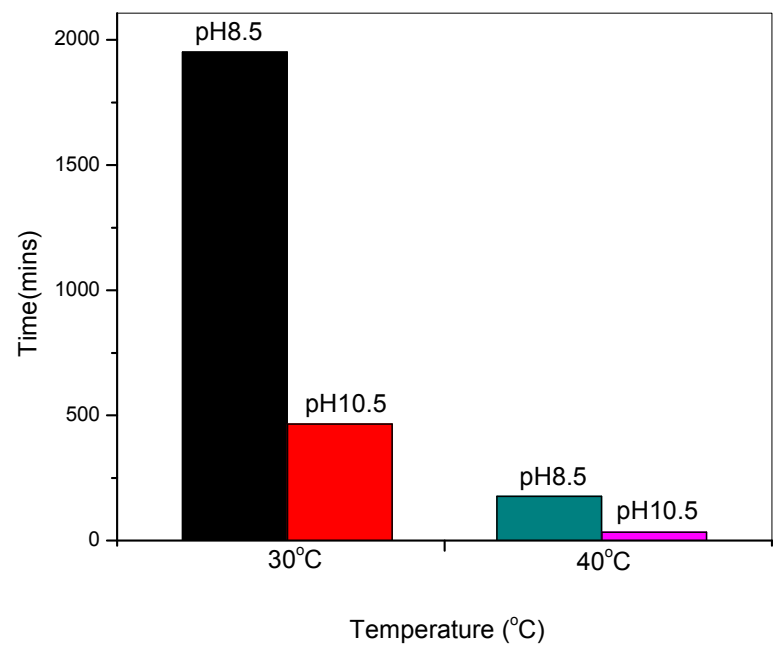

Figure 2. Latency periods at different temperatures and $\mathrm{pH}$ values for corrosion of standard aluminium pigment

\subsection{Addition of the Plant Extracts}

All gas-volumetric results of the corrosion of the aluminium pigments at $40^{\circ} \mathrm{C}$ and $\mathrm{pH} 10.5$ without and with addition of $4.0 \%(\mathrm{v} / \mathrm{v})$ of $\mathrm{CC}$ and $\mathrm{BC}$ plant extracts is summarized in Figure 3. Here also we observed the presence of latency periods which represents not only the time required to break down the pre-immersion oxide but also the time to cause the desorption of the inhibitor molecules from the aluminium surface. Figure 4 compares the latency periods of the inhibited solutions with the standard. After the latency period, the corrosion reaction initiated with a high rate.

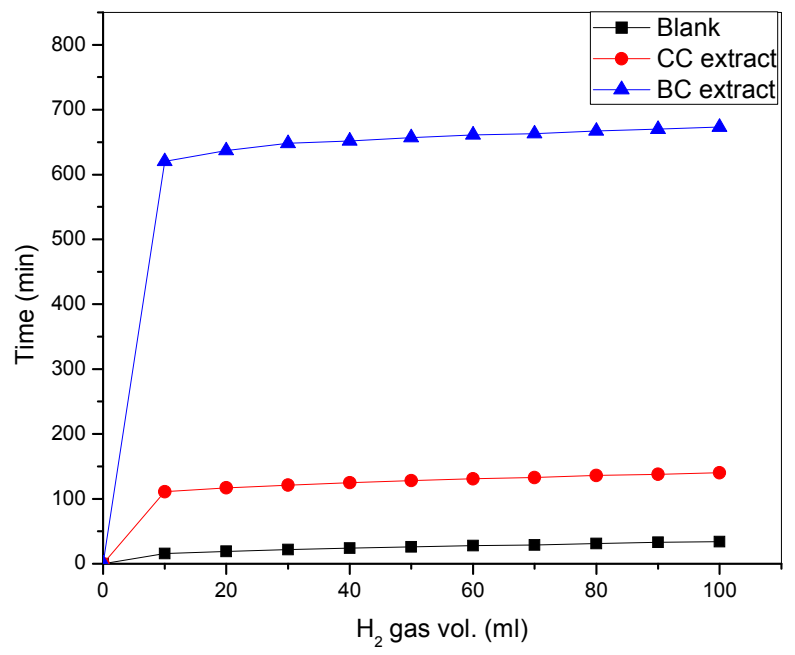

Figure 3. Hydrogen evolution plots during the corrosion of aluminium pigments in alkaline medium at $40^{\circ} \mathrm{C}$ and $\mathrm{pH} 10.5$ without and with the addition of $\mathrm{CC}$ extract and $\mathrm{BC}$ extract 
The rate of hydrogen evolution could be approximated using the following equation:

$$
\mathrm{V}=\mathrm{kt}
$$

where $\mathrm{V}$ is the volume of the evolved $\mathrm{H}_{2}$ gas at time $\mathrm{t}$ and $\mathrm{k}$ is the specific rate constant. This rate is similar beyond the latency period for each extract because once the inhibitor film is removed the underlying substrate is the same and should have similar properties. The presence of longer latency periods in the inhibited experiments is a clear indication that the plant extracts inhibited the corrosion of the aluminium pigment in the test medium.

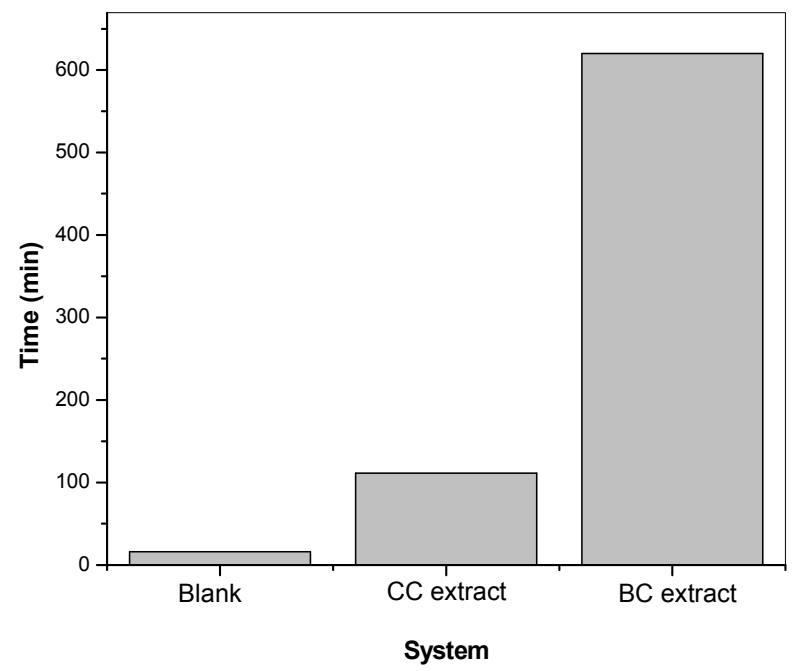

Figure 4. Effect of $\mathrm{CC}$ extract and $\mathrm{BC}$ extract on the latency periods for the corrosion of aluminium pigment in alkaline medium at $40^{\circ} \mathrm{C}$ and $\mathrm{pH} 10.5$

\subsubsection{Inhibition Efficiency}

The protective action of an organic compound during corrosion of a material is based on the adsorption ability of their molecules where the resulting adsorption film isolates the material from the corrosion medium. Consequently in inhibited solutions, the corrosion rate is indicative of the number of free sites remaining after some sites have been effectively blocked by the adsorbed inhibitor. If it is assumed that corrosion occurs only at the free sites while the covered sites have negligible corrosion rates the degree of surface coverage $(\theta)$ and hence the inhibition efficiency (IE\%) can be calculated as follows:

$$
\begin{aligned}
\theta & =1-\frac{L_{\text {free }}}{L_{\text {inh }}} \\
\mathrm{IE} \% & =1-\left(\frac{L_{\text {free }}}{L_{\text {inh }}}\right) X 100
\end{aligned}
$$

where $\mathrm{L}_{\text {free }}$ and $\mathrm{L}_{\text {inh }}$ correspond to the latency periods in the absence and in the presence of inhibitor respectively. The inhibition efficiencies values obtained are $96.6 \%$ and $85.5 \%$ for $\mathrm{BC}$ and $\mathrm{CC}$ respectively. This result shows that the longer the latency period the higher the inhibition efficiency. It is obvious that the additives displayed remarkable protective ability in the examined medium which can be attributed to chemical composition of the plant extracts which includes tannins, saponins, carbohydrates, proteins etc, some of which has been reported to retard metal dissolution (Oguzie, 2008).

Attempt was also made to establish the trend of the inhibition efficiencies of each extract on the pigment surface as a function of the volume of hydrogen evolved within a given period. The result obtained is presented Table 1 and Figure 5. A close inspection of the data shows that the efficiency of the extracts gradually diminished as more and more gas is evolved from the system resulting from continuous agitation and subsequent desorption of the inhibitor from the pigment surface. 
Table 1. Inhibition efficiencies (IE\%) of $\mathrm{CC}$ and $\mathrm{BC}$ as function of hydrogen evolved at $40^{\circ} \mathrm{C}$ and $\mathrm{pH} 10.5$

\begin{tabular}{lll}
\hline $\mathrm{H}_{2}$ Vol. & \multicolumn{2}{l}{ Inhibition efficiency $(\mathrm{IE} \%)$} \\
& $\mathrm{CC}$ & $\mathrm{BC}$ \\
\hline 10 & 85.6 & 97.4 \\
20 & 82.9 & 97.0 \\
30 & 80.2 & 96.6 \\
40 & 78.4 & 96.3 \\
50 & 76.6 & 96.0 \\
50 & 74.8 & 95.8 \\
70 & 73.9 & 95.6 \\
80 & 72.0 & 95.3 \\
90 & 70.3 & 95.1 \\
100 & 69.4 & 94.9 \\
\hline
\end{tabular}
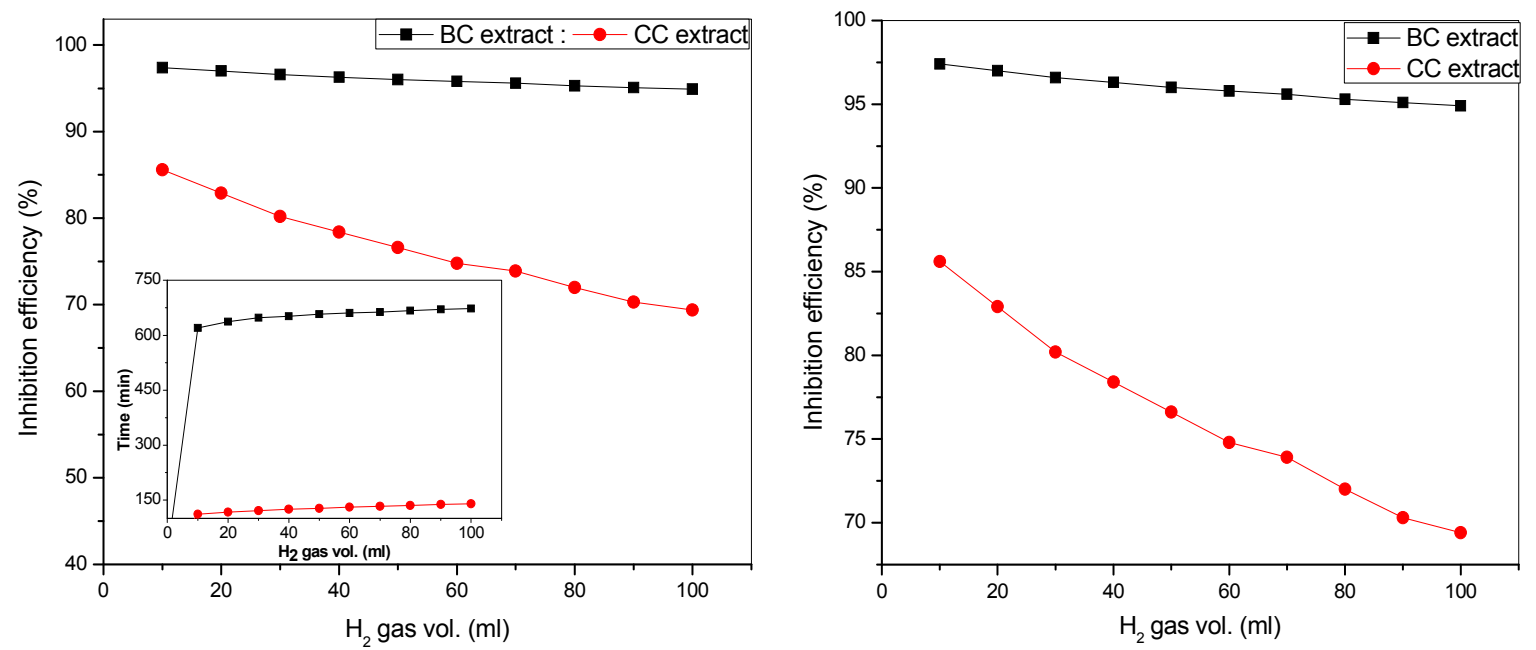

Figure 5. Inhibition efficiency of $\mathrm{BC}$ extract and $\mathrm{CC}$ extract as a function of evolved $\mathrm{H}_{2}$ gas volume. Efficiency gradually diminishes as more and more gas is evolved from the system

\subsubsection{Effect of Concentration}

To establish the effect of concentration on latency and hence the inhibition efficiency, $\mathrm{CC}$ which showed the lower latency period was selected for further investigation. Figure 6 summarizes the result obtained with addition of increasing amounts of CC (4.0-10.0\%). Figure 7 is the plot of latency periods with concentration which shows that the latency period is also concentration dependent. With increasing concentration of extract the corrosion reaction was further delayed and this also translates to higher inhibition efficiency. The higher degree of protection obtained at higher concentration is as result of higher degree of surface coverage resulting from enhanced inhibitor adsorption. The trend of inhibition efficiency with time showed that it is possible to achieve $100 \%$ coverage and it also shows that at higher concentration adsorption predominates over the tendency to desorb. This fact is corroborated with the data presented in Table 2 which represents the trend of inhibition efficiency as a function of volume of hydrogen evolved at the different concentrations. 
Table 2. Trends of inhibition efficiency as a function concentration of $\mathrm{CC}$ during the corrosion of aluminium pigment in alkaline medium

\begin{tabular}{lllll}
\hline Vol. $\mathrm{H}_{2}$ & $\mathrm{IE} \%(4.0)$ & $\mathrm{IE} \%(6.0 \%)$ & $\mathrm{IE} \%(8.0)$ & IE\%(10.05) \\
\hline 10 & 85.5 & 95.3 & 98.3 & 99.5 \\
20 & 83.8 & 94.8 & 98.3 & 99.4 \\
30 & 81.8 & 94.2 & 98.1 & 99.3 \\
40 & 80.8 & 93.8 & 97.9 & 99.3 \\
50 & 79.7 & 93.5 & 97.8 & 99.2 \\
60 & 78.5 & 93.1 & 97.6 & 99.2 \\
70 & 78.2 & 92.9 & 97.5 & 99.2 \\
80 & 77.2 & 92.5 & 97.4 & 99.1 \\
90 & 76.1 & 92.1 & 97.2 & 99.1 \\
100 & 75.7 & 91.9 & 97.1 & 99.0 \\
\hline
\end{tabular}

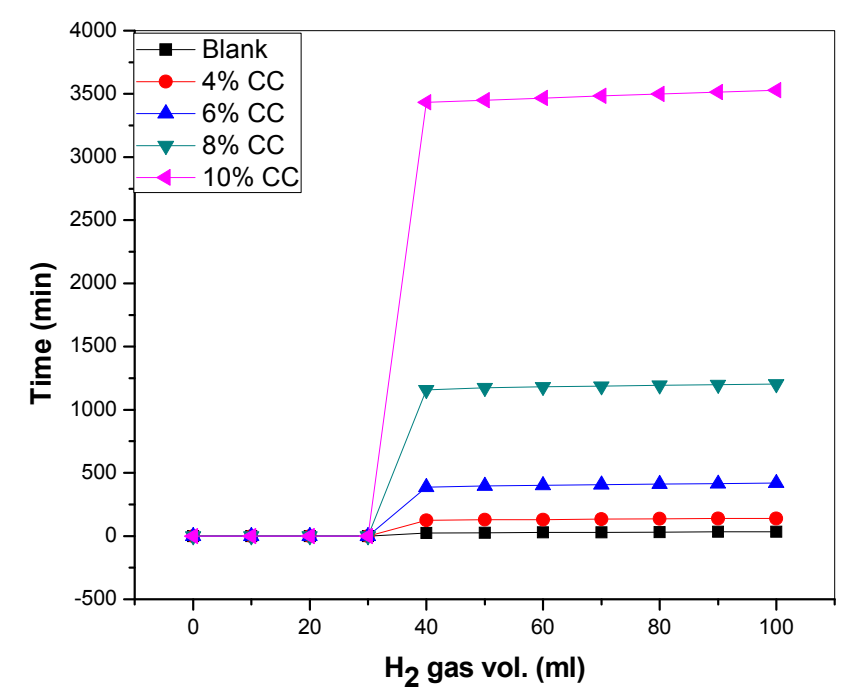

Figure 6. Effect of increasing the concentration of $\mathrm{CC}$ extract on the corrosion of aluminium pigment in alkaline medium at $40^{\circ} \mathrm{C}$ and $\mathrm{pH} 10.5$

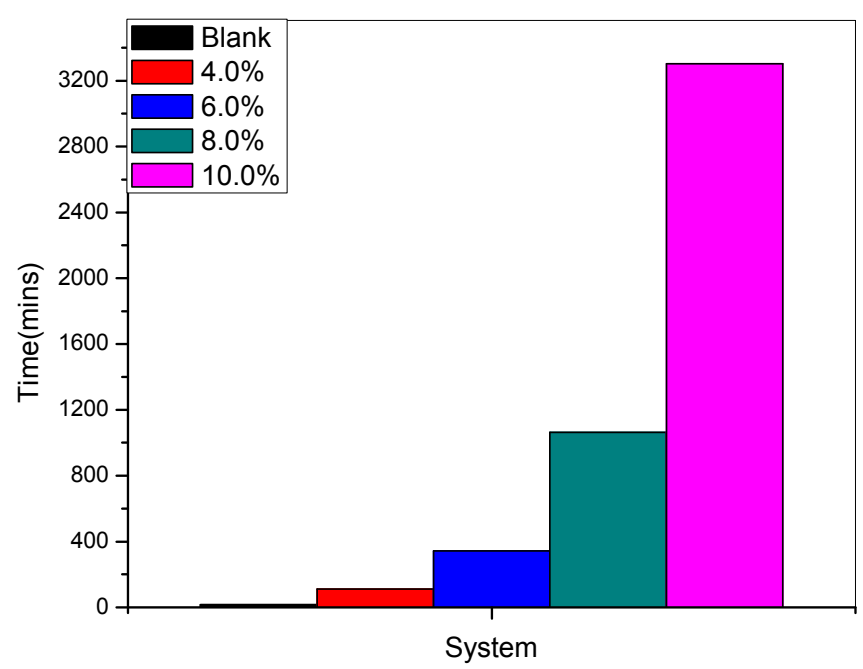

Figure 7. Latency periods as a function of the concentration CC during the corrosion of aluminium pigment in alkaline medium 


\subsubsection{Adsorption Consideration}

It is widely acknowledged that organic inhibitors function by adherence to a corroding metal surface through the metal ions still in place at the lattice and thereby retard metal dissolution by virtue of adsorption. A given inhibitor acts by means of a specific adsorption mechanism that depends on the composition of the metal and corrodent, inhibitor structure and concentration as well as temperature. Generally, an inhibitor may either be physically or chemically adsorbed on the metal surface. Although the border line between the two mechanisms is often blurred and their distinction difficult, a number of experimental criteria make this possible. The energy of adsorption could not be calculated due to the unknown molecular mass of the extract. Hence the criterion based on the change of activation energy in the inhibited system with respect to the uninhibited one, has been applied. It is usually argued that upward or downward changes in the activation may express the advantageous physical or chemical bonding (Martinez, 2003; Popova et al., 2003). The effective energy of activation $\mathrm{E}_{\mathrm{a}}$ was calculated by application of the Arrhenius relation:

$$
\ln V=-\frac{E_{a}}{R T}+\text { cons } \tan t
$$

Where $\mathrm{k}$ is the specific rates constant defined by Eq.3, $\mathrm{R}$ is the universal gas constant and $\mathrm{T}$ is the thermodynamic temperature. For the purpose of calculating $E_{a}$, the corrosion rates were measured at $40^{\circ} \mathrm{C}$ and at the inhibitor concentration equal to $4.0 \%(\mathrm{v} / \mathrm{v})$. The respective energies of activation were 55.02, 56.40, 71.40 $\mathrm{kJmol}^{-1}$ for the blank CC and $\mathrm{BC}$ respectively. The increase of the activation energy in the inhibited systems indicates preferential physical bonding of the inhibitor molecules to the pigment surface.

\subsection{Theoretical Consideration}

Experimental results show that the corrosion-inhibiting efficacy of the plant extracts result from adsorption of the extract organic matter on the corroding metal surface. This normally results from Lewis acid-base interactions in which the metal and inhibitor molecules act as a Lewis acid and Lewis base, respectively, and their interaction is accomplished by favorable overlap of frontier orbitals and sharing of electrons between the inhibitor and the partially filled d-orbitals of the metal (Oguzie et al., 2010). A practical route to studying the complex processes associated with metal-inhibitor interactions at the molecular level involves computer simulations of suitable models, and density functional theory (DFT) has been used widely in this regard (Rodriquez et al., 2006). The approach we used with the plant extracts in view of their complex chemical composition involved qualitative characterization of the phytochemical constituents coupled with elucidation of their molecular structures. We then model the molecular structures using a combination of DFT-based quantum-chemical calculations and molecular dynamics simulations to theoretically evaluate the inhibiting potential based on structure-activity relationships such as the HOMO (highest occupied molecular orbital) energy, the LUMO (lowest unoccupied molecular orbital) energy, the gap energy, ( $\triangle \mathrm{E}, \mathrm{E}_{\mathrm{LUMO}}-\mathrm{E}_{\mathrm{HOMO}}$ ), the dipole moment $(\mu)$. We have performed such calculations to model the adsorption structures of the major chemical constituents of the extracts: L-lysine (LY) and cystein (CY) from CC; Emodine (EMD) and Glycoside (GLY) from $\mathrm{BC}$ extract. The ground state geometry of the inhibitor as well as the nature of its frontier molecular orbitals namely, the HOMO and LUMO are all involved in the activity of the inhibitor and these properties were calculated by means of the DFT electronic structure program $\mathrm{Dmol}^{3}$ available in material studio version 4.0 and presented in Figures 8-11. 


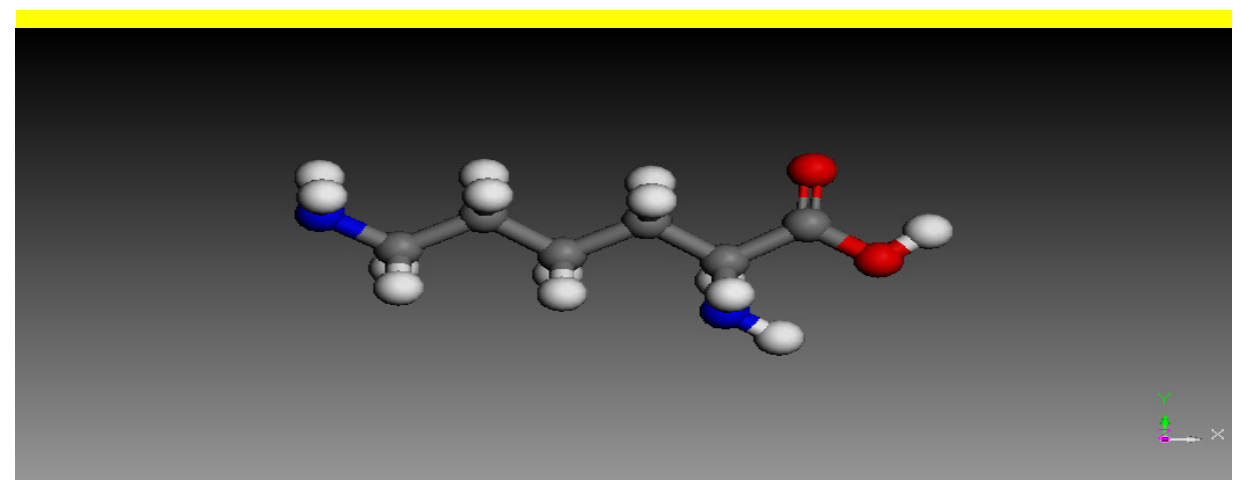

(8a)

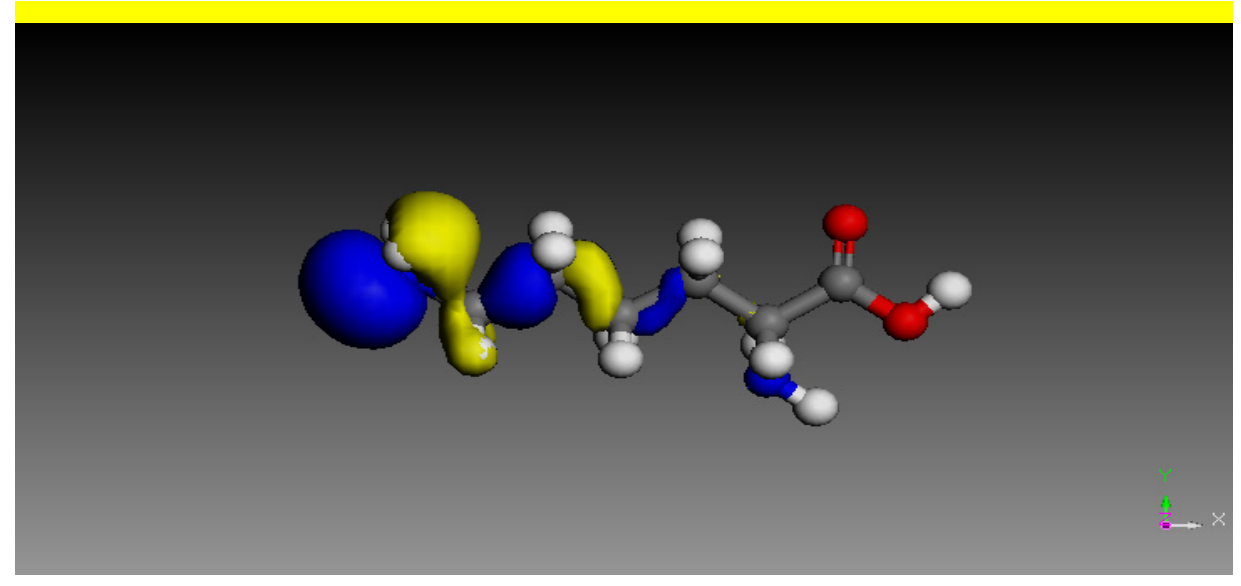

(8b)

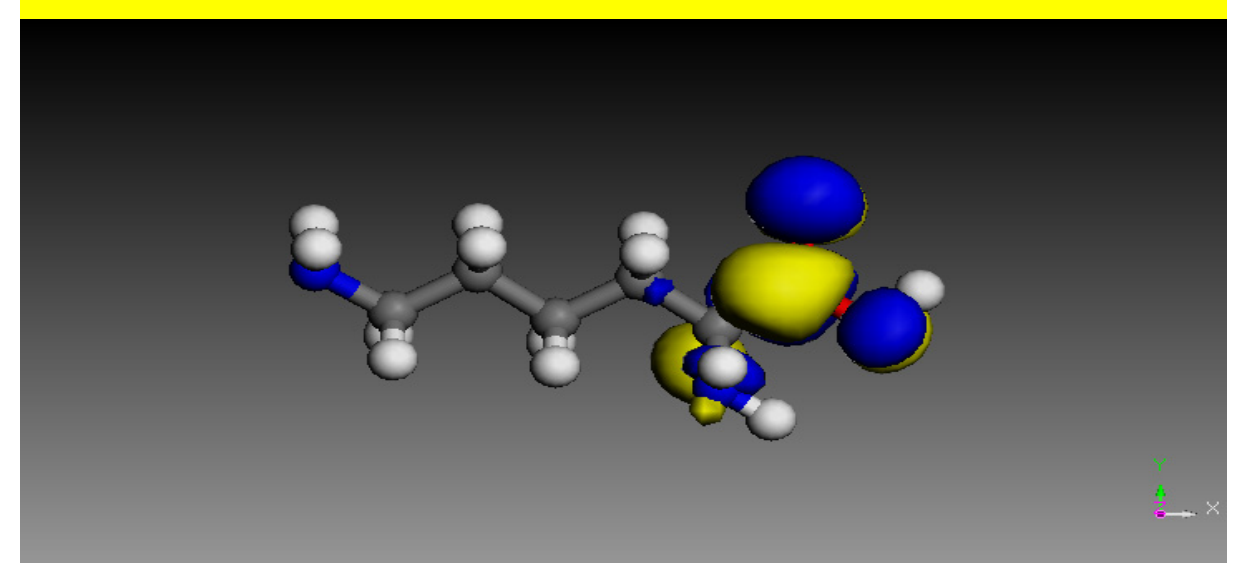

(8c)

Figure 8. Electronic properties of L-lysine (a) optimized structure (b) HOMO orbital (c) LUMO orbital (Atom legend: white $=\mathrm{H}$ :, gray $=\mathrm{C}$, red $=\mathrm{O}$, blue $=\mathrm{N}$, yellow $=\mathrm{S}$ ) 


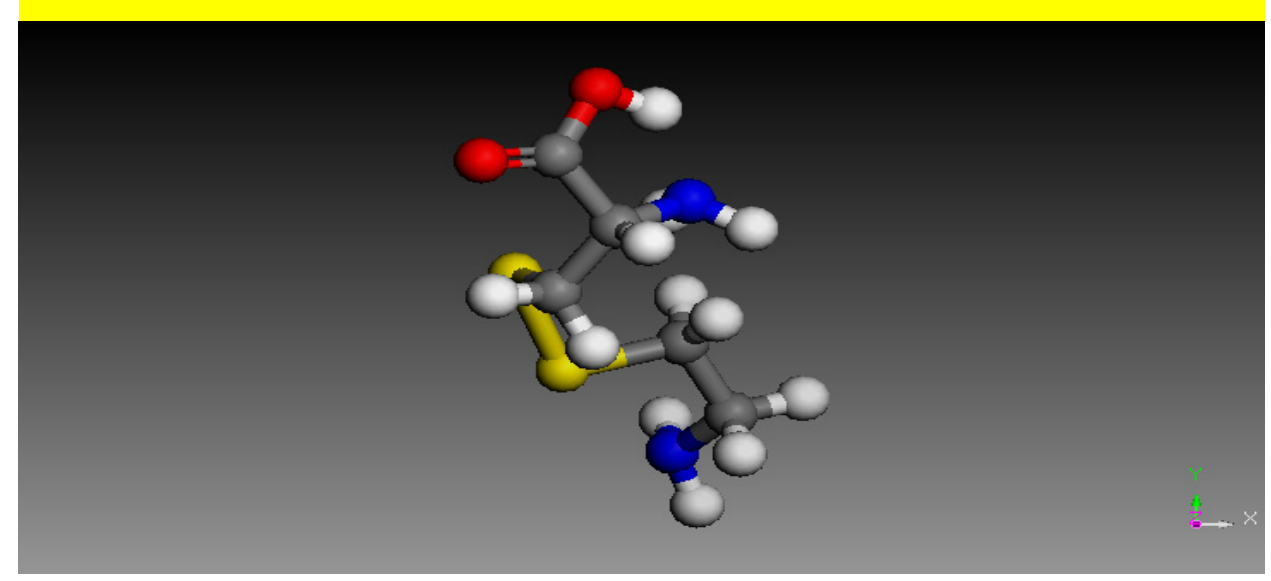

(9a)

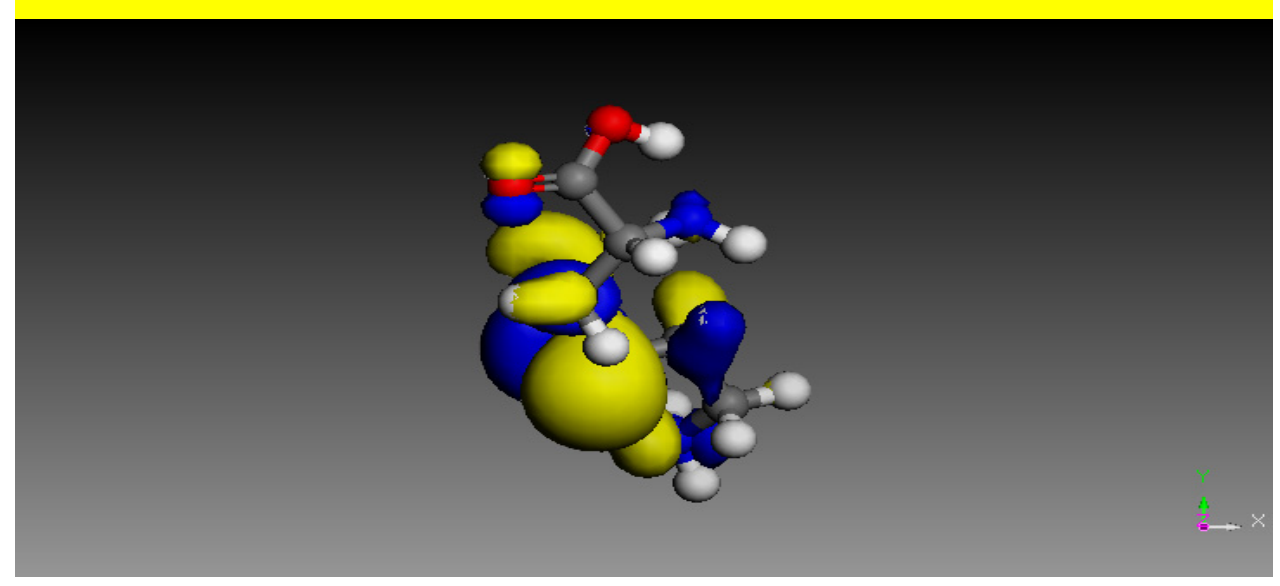

(9b)

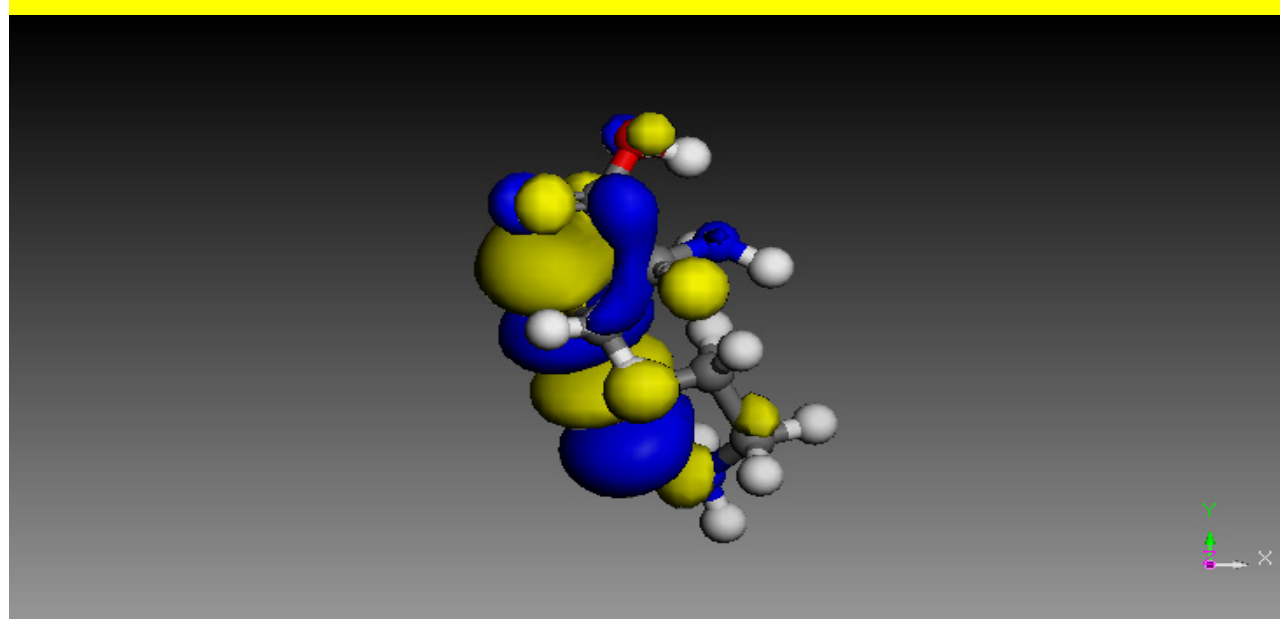

$(9 \mathrm{c})$

Figure 9. Electronic properties of cystein (a) optimized structure (b) HOMO orbital (c) LUMO orbital (Atom legend: white $=\mathrm{H}$ :, gray $=\mathrm{C}$, red $=\mathrm{O}$, blue $=\mathrm{N}$, yellow $=\mathrm{S}$ ) 


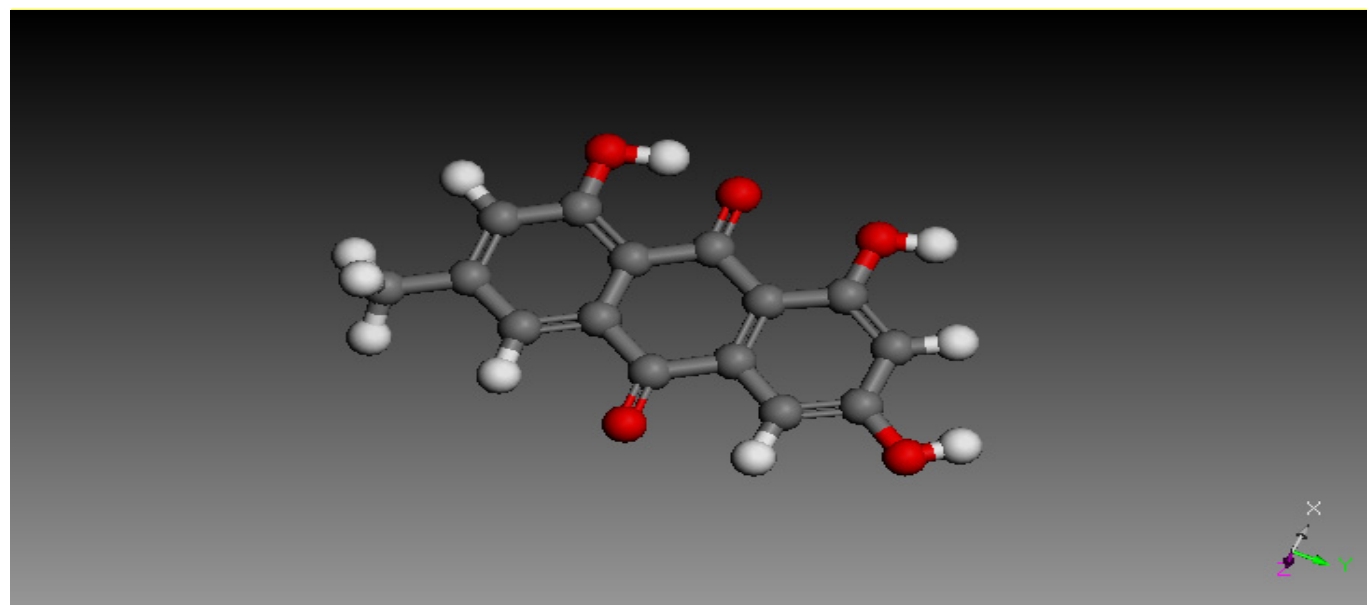

(10a)

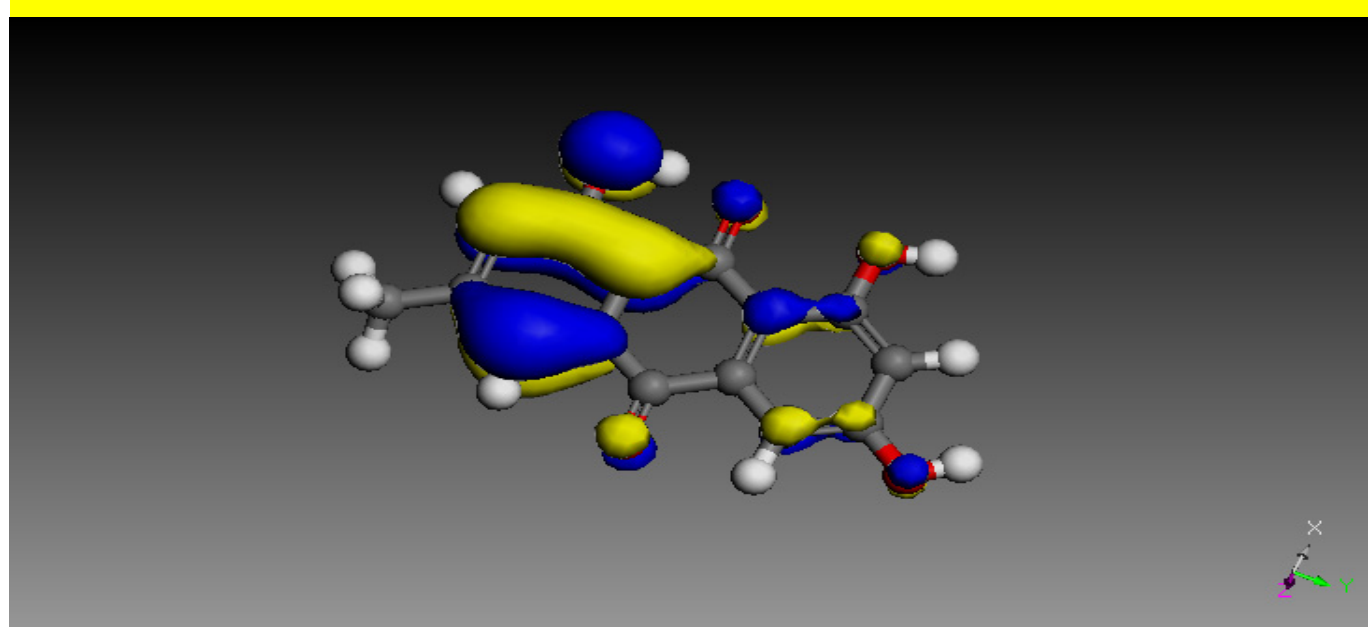

(10b)

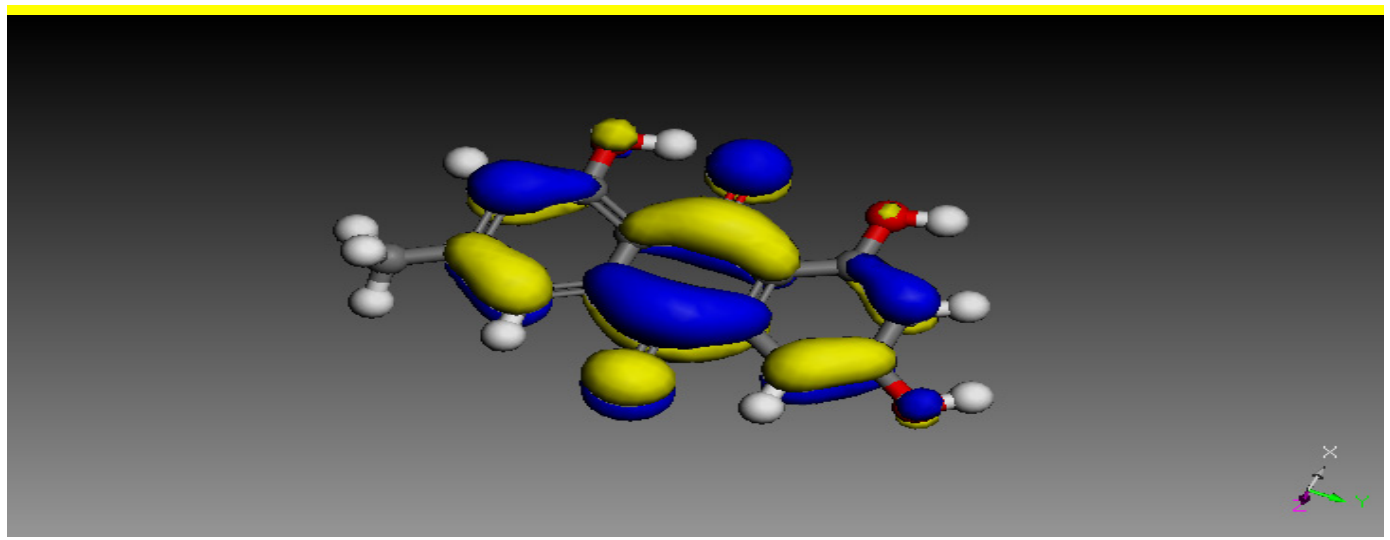

(10c)

Figure 10. Electronic properties of Emodine (a) optimized structure (b)HOMO orbital (c) LUMO orbital (Atom legend: white $=\mathrm{H}$ :, gray $=\mathrm{C}$, red $=\mathrm{O}$, blue $=\mathrm{N}$, yellow $=\mathrm{S}$ ) 


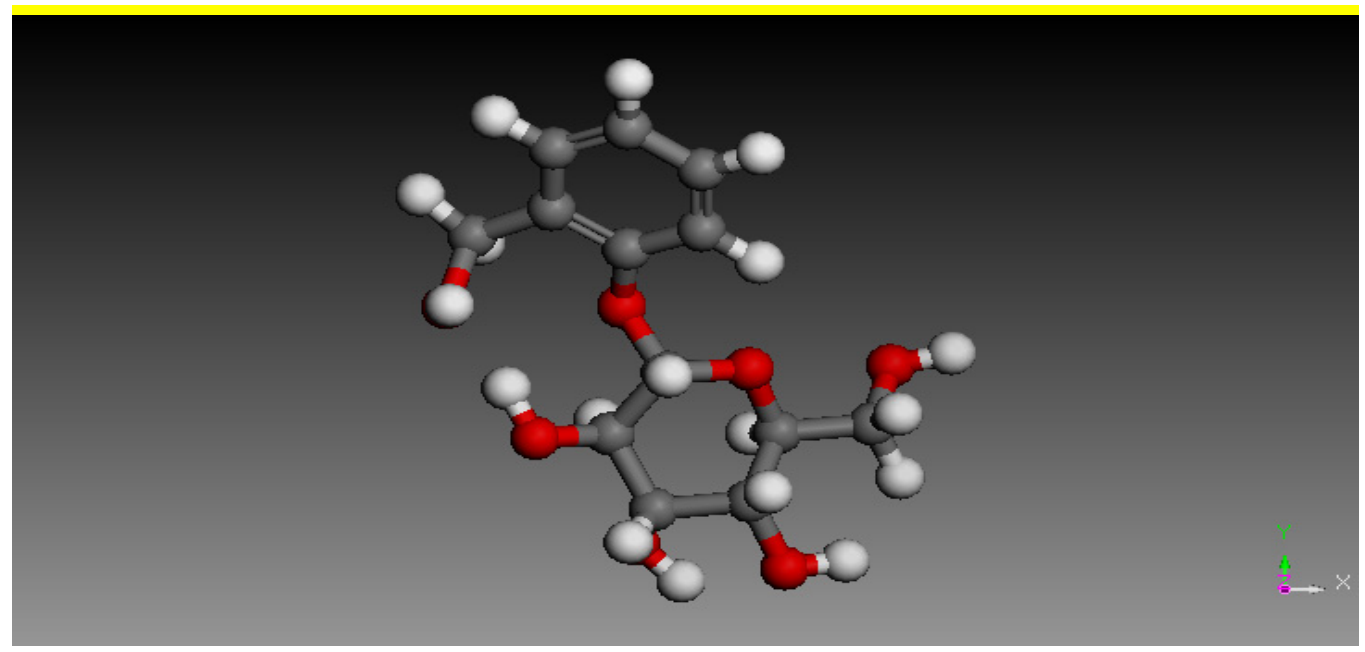

(11a)

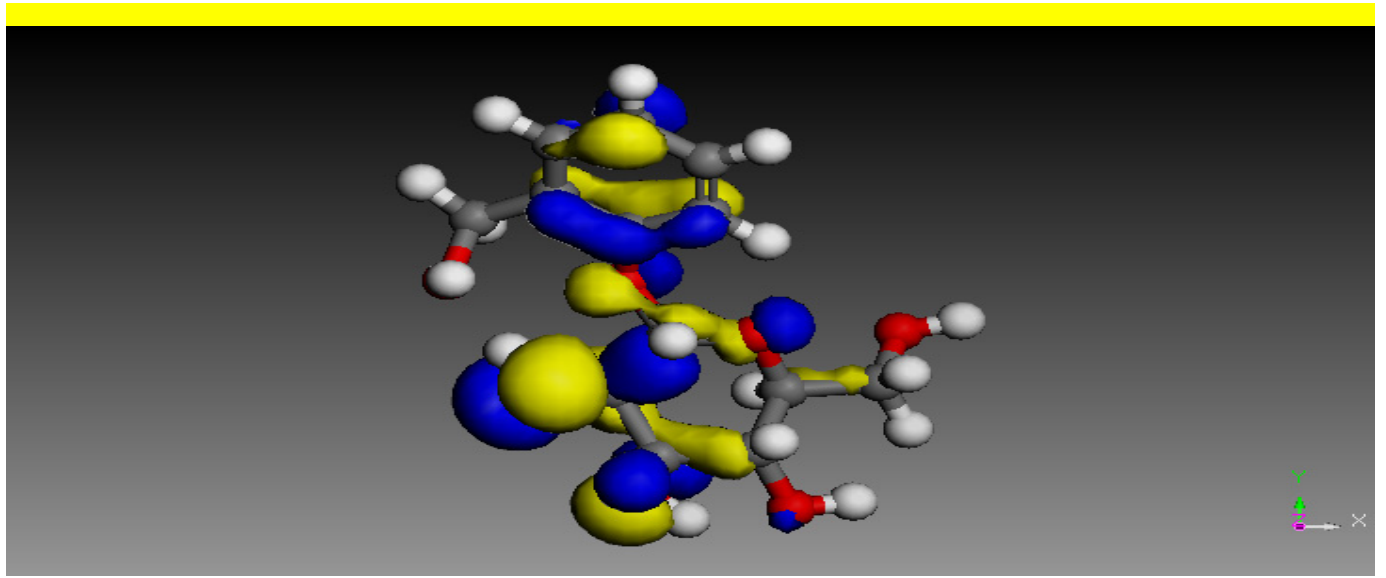

(11b)

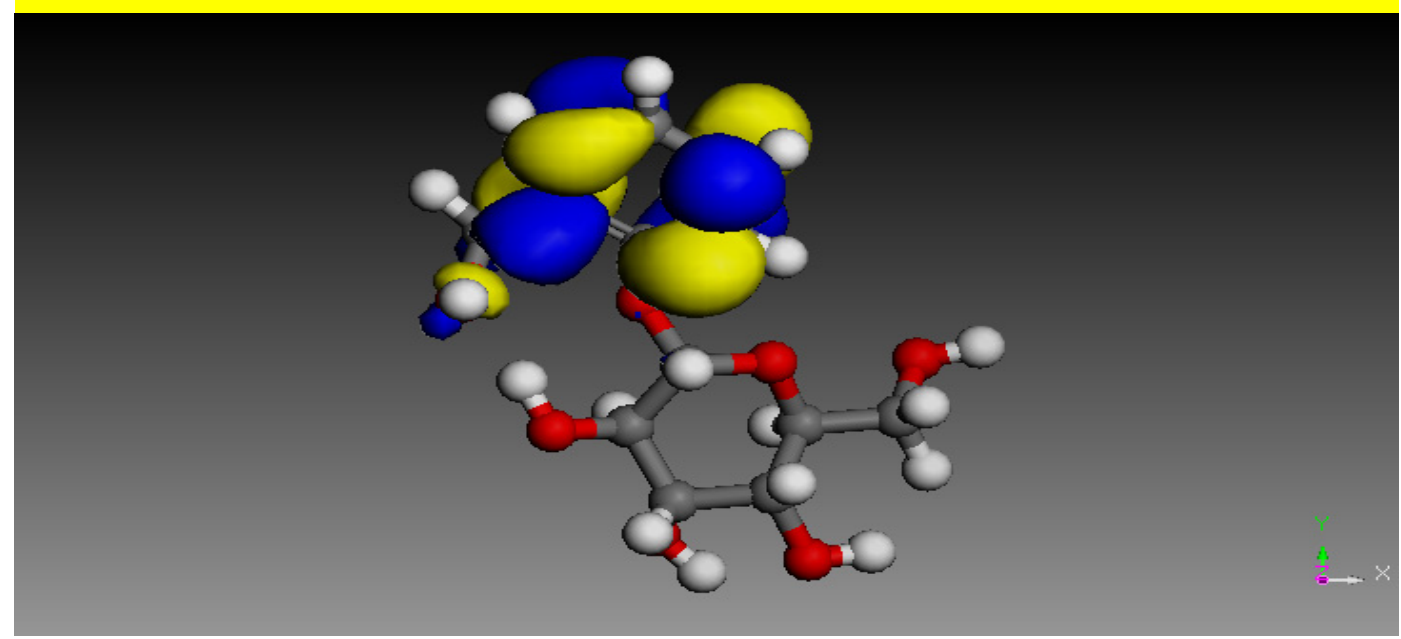

(11c)

Figure 11. Electronic properties of Glycoside (a) optimized structure (b) HOMO orbital (c) LUMO orbital (Atom legend: white $=\mathrm{H}$ :, gray $=\mathrm{C}$, red $=\mathrm{O}$, blue $=\mathrm{N}$, yellow $=\mathrm{S}$ )

The regions of highest electron density (HOMO) are the sites at which electrophiles attack and represent the active centers, with the utmost ability to bond to the metal surface, whereas the LUMO orbital can accept the 
electrons in the d-orbital of the metal using antibonding orbitals to form feedback bonds (Xia et al., 2008). Table 3 provides some quantum-chemical parameters related to the molecular electronic structure of the most stable conformation of the molecules. High values of $\mathrm{E}_{\text {номо }}$ indicate the disposition of the molecule to donate electrons to an appropriate acceptor with vacant molecular orbitals. Also an increase in the values of $\mathrm{E}_{\text {Номо }}$ can facilitate adsorption and therefore the inhibition efficiency (Rodiquez et al., 2006). The obtained values of $\mathrm{E}_{\mathrm{HOMO}}$ corresponding to the structures obtained have a small difference between them. This indicates a very similar capacity for charge donation to the metallic surface. In the same way, low values of the energy of the gap, $\Delta \mathrm{E}$, will render good inhibition efficiencies since the energy to remove an electron from the last occupied orbital will be minimized. The dipole moment $(\mu)$ is the first derivative of the energy with respect to an applied electric field and is a measure of the asymmetry in the molecular charge distribution. A low value of the $\mu$ favors accumulation of inhibitor molecules on the metal surface and is also an indication of the hydrophobic character of the molecule. Values of $\mu$ ranging from 3 to 5 have been reported in the literature (Cruz et al., 2003, Roque et al., 2008; Rodiquez et al., 2006).

The local reactivity of the molecules was analyzed by means of the Fukui indices (FI) since they indicate the reactive regions in terms of nucleophilic $\left(\mathrm{f}^{+}\right)$and electrophilic (f) attack. The $\mathrm{f}^{+}$, measures the changes of the density when the molecule gains electrons and it corresponds to the reactivity with respect to nucleophilic attack. On the hand, f corresponds to the reactivity with respect to electrophilic attack or when the molecule loss electrons. We observed that the FI functions of all the molecules correspond with the HOMO locations, indicating the zones through which the molecule will be adsorbed onto the pigment surface.

Table 3. Calculated quantum chemical properties of the studied compounds

\begin{tabular}{lllll}
\hline Compound $\rightarrow$ & LY & CY & EMD & GLY \\
\hline Property & & & & \\
$\mathrm{E}_{\mathrm{HOMO}}(\mathrm{eV})$ & -5.587 & -6.183 & -5.905 & -5.766 \\
$\mathrm{E}_{\mathrm{LUMO}}(\mathrm{eV})$ & -1.660 & -2.091 & -3.875 & -1.294 \\
$\Delta \mathrm{E}(\mathrm{eV})$ & 4.212 & 4.092 & 2.03 & 4.47 \\
$\mu($ Debye $)$ & 2.515 & 8.675 & 3.898 & 5.687 \\
$\mathrm{E}_{\text {Bind }}$ on pure $\mathrm{Al}(\mathrm{Kcal} / \mathrm{mol})$ & -56.180 & -50.64 & 59.95 & -57.68 \\
\hline
\end{tabular}

The chemical adsorption is indeed the most important type of interaction between the metallic surface and an inhibitor molecule. For this to be possible, the adsorbed species must be in contact with surface. In this process, a coordinated bond that involves the electro transference from the inhibitor system towards the metallic surface is formed. The electron transference is facilitated when the inhibitor molecule has a lone pair of electrons without share in the donating atom of the functional group, and the availability of n-electrons due to the presence of the double bonds or aromatic rings in the structure.

From the theoretical calculations carried out with the neutral forms of these molecules, it can be concluded that the structural and electronic properties of these molecules are very similar. Consequently, theoretical calculations with only the neutral form of these molecules could be a good approach for the study of their potential inhibition capacity for metal corrosion inhibition. However, certain features point toward the individual corrosion-inhibiting efficacies of the molecules. For instance, the calculations indicate that the CY molecule has the highest HOMO energy $(6.183(\mathrm{eV}))$, indicating a stronger tendency of the molecule to donate electrons to appropriate acceptor molecules of low empty molecular orbital energy. GLY has the lowest $\mathrm{E}_{\mathrm{LUmo}}$ value, showing that the molecule would readily accept electrons from the metal d-orbital. EMD on the other hand has the lowest $\Delta \mathrm{E}$ value, which corresponds to higher stability of the (Al-EMD) complex as well as high values of the dipole moment and polarizability, which describe the reactivity of the inhibitor molecule toward the metal surface.

\subsubsection{Molecular Dynamics}

We also performed molecular dynamics (MD) simulations to illustrate the adsorption of the molecules onto both the pure and corroding metal surface at a molecular level. This was achieved using Forcite quench molecular dynamics in the MS Modeling 4.0 software to sample many different low-energy configurations and identify the low energy minima (Oguzie et al., 2010). Among the different steps involved in the modeling approach was the construction of the metal surface and the addition of the inhibitor molecule near to the surface followed by the 
geometry optimization calculation. For both pure and oxide (Al) crystals the $\left(\begin{array}{lll}1 & 1 & 0\end{array}\right)$ plane is the most stable and was chosen for this study. Calculations were carried out in a $12 \times 8$ supercell using the Condensed Phase Optimized Molecular Potentials for Atomistic Simulation Studies (COMPASS) force field and the Smart algorithm. Temperature was fixed at $350 \mathrm{~K}$, with NVE (microcanonical) ensemble, with a time step of $1 \mathrm{f} \mathrm{s}$ and simulation time 5 ps. The system was quenched every 250 steps. Once the model has been optimized with suitable forcefield (COMPASS), we were able to simulate a substrate (metal surface) loaded with an adsorbate (inhibitor).

Binding energy is an important factor to characterize the adsorption ability of an inhibitor molecule onto the metal surface which can be calculated by the following equation:

$$
\mathrm{E}_{\text {Bind }}=\mathrm{E}_{\text {Total }}-\left(\mathrm{E}_{\mathrm{Al}}+\mathrm{E}_{\text {inh }}\right)
$$

with $\mathrm{E}_{\mathrm{Al}}$ and $\mathrm{E}_{\text {inh }}$ being the total energy of the $\mathrm{Al}$ crystal and the inhibitor molecule respectively. In each case the $\mathrm{E}_{\mathrm{Al}}$ and $\mathrm{E}_{\text {inh }}$ were calculated by taking the average of the energies of six structures of lowest energy. The values of the binding energies for the components of $\mathrm{CC}$ and $\mathrm{BC}$ on both pure and oxide $\mathrm{Al}(110)$ are included in Table 3 . The molecules show similar binding energies on either surfaces but with much higher values on the oxide surface. For the $\mathrm{Al}_{2} \mathrm{O}_{3}$ surface, cation $\mathrm{Al}^{3+}$ presents anodic reaction center, which can bind to the nucleophilic attacking center in the inhibitor molecules. Anion $\mathrm{O}^{2-}$ presents as a cathodic reactive center, which can bind to nucleophilic centers in inhibitor molecules. Therefore, inhibitor molecule can be adsorbed onto the $\mathrm{Al}_{2} \mathrm{O}_{3}$ surface through interaction with these sites, and as a result, the transport of corrosive species is restricted from solution to metal surface. Then electrochemical reactions are retarded.

The value of the binding energy is negative which means that adsorption was spontaneous and this corresponds to a more stable adsorption structure. Several authors agree that high binding energy values reflect the high stability of the formed complex and accordingly increase in inhibition efficiency (Xia et al., 2008, Zhang et al., 2007) and this observation is consistent with our experimental result. The adsorption models of the molecules have been omitted since the key interest here is on the binding energy.

\section{Conclusion}

The results obtained from this study indicate that all the extracts inhibited the corrosion process by virtue of adsorption on the surface of the aluminium pigment leading to an extended latency periods compared to that of the uninhibited aluminium pigment. The latency period was found to depend on $\mathrm{pH}$, temperature, stirring rate, concentration and plant type. A linear correlation was obtained between inhibition efficiency and duration of latency for each extract. Molecular modeling was used to evaluate the structure, electronic reactive parameters of the plant extracts in relation to their effectiveness as corrosion inhibitors.

\section{Acknowledgements}

The authors are grateful to Mr. DI. Ingo Giesinger of Benda-Lutz, who provided the aluminium pigment and other chemicals and TWAS for the funding of the research.

\section{References}

Abdel-Gaber, A. M., Khamis, E., Abo-ELDahab, H., \& Adeel, Sh. (2008). Inhibition of aluminium corrosion in alkaline solution using natural compounds. Mat. Chem \& Phy., 109, 297-305. http://dx.doi.org/10.1016/j.matchemphys.2007.11.038

Avwiri, O., Igho, F. O. (2003). The inhibitive action of Veronia amygdalina on the corrosion of aluminium alloy in acidic solutions. Material Letters, 57, 3705. http://dx.doi.org/10.1016/S0167-577X(03)00167-8

Babic-Samardzija, K., \& Hackerman, N. (2006), Iron corrosion inhibition with dihydrobis and hydrotris-(1-pyrazolyl) borates, Anti-corrosion. Method M., 53, 19-29.

Babic-Samardzija, K., Khaled, K. F., \& Hackerman, N. (2005), N-heterocyclic amines and derivatives as corrosion inhibitors for iron in perchloric acid, Anti-corrosion. Method M., 52, 11-21.

Bentiss, F. M., Traisnel, M., Vezin, H., \& Lagrenée, M. (2003). linear resistance model of the inhibition mechanism of steel in $\mathrm{HCl}$ by triazole and oxadiazole derivatives: structure-activity correlations. Corros. Sci., 45, 371-380. http://dx.doi.org/10.1016/S0010-938X(02)00102-6

Besold, R., Reiber, W., \& Roth, E. (1991). Farbe Lack, 97(4), 311.

Cruz, J., Martinez, R., Genesca, J., \& Garcia-Ochoa, E. (2004). Experimental and theoretical study of 1-(2-ethylamino)-2-methylimidazoline as an inhibitor of carbon steel corrosion in acid media. $J$. of Electroanalytical Chemistry, 566, 111-121. http://dx.doi.org/10.1016/j.jelechem.2003.11.018 
El-Hosary, A., Saley, R. M., \& Sharma Eldin, A. M. (2006). Corrosion inhibition of aluminium and zinc in $\mathrm{HCl}$ using Hibiscus subdariffa extract. Corrosion Science, 897.

Gokhan, Gece. (2008). The use of quantum chemical methods in corrosion inhibitor studies. Corros. Science, pp. 2981-2992.

Herman, T. (1994). Reactivity of the aluminium surface in aqueous solutions. TALAT lectures, 5102, EAA.

Jain, T., Chowdhary, R., \& Mathur, S. P. (2006). The inhibitive action of the acid extracts of seeds leaves and barks from the Ficus virens plants towards acid corrosion of aluminium. Material Corrosion, $57,422$. http://dx.doi.org/10.1002/maco.200503913

Jiang, J. Y., \& Geng, D. S. (2008). Anti-inflammatory effects of berberine. Chin. Pharmacol. Bull., 14, $434-437$.

Karlson, P., Palmqvist, A. E. C., \& Holmberg, K. (2006). Surface modification of aluminium pigment inhibition, Advances in Colloid and Interface Science, pp.121-134. http://dx.doi.org/10.1016/j.cis.2006.11.010

Kiechl, A., \& Greiwe, K. (1999). Encapsulated aluminium pigments. Progress in Organic Coatings.

Kruba, L., \& Stucker, P. (2007). Inhibitor prevents hydrogen emission from zinc in waterborne alkyds. ECJ, 12, 40-45, Vincentz Network, Hannover.

Lagrenée, M., Mernari, B., Chaibi, N., Traisnel, M., Vezin, H., \& Bentiss, F. (2001). Investigation of the inhibitive effect of substituted oxadiazoles on the corrosion of mild steel in $\mathrm{HCl}$ medium. Corros. Sci., 43, 951-962. http://dx.doi.org/10.1016/S0010-938X(00)00076-7

Levine, I. N. (1991). Quantum Chemistry. New Jersey: Prentice Hall.

Liu, H., Ye, H., \& Tang, X. (2007). Aluminum pigment encapsulated by in situ copolymerization of styrene and maleic acid. Applied Surface Science, 254, 616-620. http://dx.doi.org/10.1016/j.apsusc.2007.06.047

Martinez, S. (2002). Inhibitory mechanism of mimosa tannin using molecular modeling. Mater. Chem. Phys., 9288, 1-6.

Martinez, S., \& Stagljar, I. (2003). Correlation between the molecular structure and the corrosion inhibition efficiency of Chestnut tannin in acidic solutions. J. of Mol. Structure (Theochem), 640, 167-174. http://dx.doi.org/10.1016/j.theochem.2003.08.126

Muller, B. et al. (1997). Inhibition of Corrosion of aluminium pigments by different styrene- maleic acid copolymers. Material Corrosion, 48(2), 95.

Muller, B. (1995a). Stabilizing of Aluminium pigments in aqueous alkaline medium by styrene copolymers. $J$. of Coatings Tech, 67(846), 59.

Muller, B. (1999). Polymeric Corrosion inhibitors for aluminium pigments. Reactive and functional polymers, 39 , 165-177.

Muller, B. (2000). Effects of saccharides, reducing sugars-fructose and mannose on the corrosion of aluminium and zinc in alkaline media. Corrosion Science, 44, 1583

Muller, B. (2004). Citric acid as corrosion inhibitor for aluminium pigment. Corrosion Science, 46, $159-167$. http://dx.doi.org/10.1016/S0010-938X(03)00191-4

Muller, B., \& Holland, A. (1997). Stabilizing of Aluminium pigments in Water-Borne systems by paint resins. Surf. Coat. Int. (JOCCA), 80(7), 321.

Muller, B., \& Schmelich, T. (1995b). High-molecular weight styrene-maleic acid copolymers as corrosion

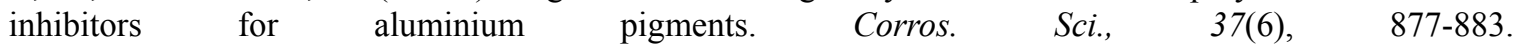
http://dx.doi.org/10.1016/0010-938X(94)00171-2

Muller, B., Oughourlian, M. C., \& Triantallidis, D. (2001b). Stabilization of aluminium in waterborne paints. $J$. of Coating Technology, 73, 917.

Muller, B., Scubert, M., \& Oughourlian, C. (2001a). Corrosion inhibition of aluminium and zinc pigments by copolymers. Pigment and Resin Technology, 30(1), 6-12. http://dx.doi.org/10.1108/03699420110364110

Oguzie, E. E. (2007), Corrosion inhibition of aluminium in acidic and alkaline media by Sansevieria trifasciata extract. Corrosion Science, 49, 1527-1549. http://dx.doi.org/10.1016/j.corsci.2006.08.009

Oguzie, E. E. (2008). Evaluation of the inhibitive effect of plant extracts on the acid corrosion of mild steel. Corrosion Science, 50, 2993-2998. http://dx.doi.org/10.1016/j.corsci.2008.08.004 
Oguzie, E. E., Enenebeaku, C. K., Akalezi, C. O., Okoro, S. C., Ayuk, A. A., \& Ejike, E. N. (2009). Adsorption and corrosion-inhibiting effect of Dacryodis edulis extract on low-carbon-steel corrosion in acidic media. $J$. of Coll. \& Interface Sci., 349, 283-292. http://dx.doi.org/10.1016/j.jcis.2010.05.027

Oguzie, E. E., Onuchukwu, A. I., Okafor, P. C., \& Ebenso, E .E. (2006). Corrosion inhibition and adsorption behaviour of Ocimum basilicum extract on aluminium. Pigment and resin tech., 15(2), 65-70.

Popova, A., Sokolova, E., Raicheva, S., \& Christov, N. (2003). AC and DC study of the temperature effect on mild steel corrosion in acid media in the presence of benzimidazole derivatives. Corrosion Science, 45, 33-58. http://dx.doi.org/10.1016/S0010-938X(02)00072-0

Priya, L. S., Chitra, A., Rajendra, S., \& Anuradha, K. (2005). Corrosion behaviour of aluminium in rain water containing garlic extracts. Surface Engr., 21(3), pp. 229-231. http://dx.doi.org/10.1179/174329405X50073

Rehan, H. H. (2003). Evaluation of the water extracts of Phoenix dactylifera, Lawsonia inermis and Zea mays for corrosion inhibition of steel, aluminium, copper and brass in acid, chlorides and sodium hydroxide solutions. Material Wissenschaft und Werkstiffechnik, 34, 232.

Reisser, W., Fetz, A., \& Roth, E. (19995). Waterborne Coatings and Additives. Cambridge: The Royal Society of Chemistry, 180.

Rodriguez-Valdez, L. M., Villamisar, W., Casales, M., Gonzalez-Rodriguez, J. G., Martinez-Villafane, A., Martinez, L., \& Glossman-Mitnik, D. (2006). Computational simulations of the molecular structure and corrosion properties of amidoethyl, aminoethyl and hydroxyethyl imidazolines inhibitors. Corrosion Science, 48, 4053-4064. http://dx.doi.org/10.1016/j.corsci.2006.05.036

Roque, J. M., Pandiyan, T., Cruz, J., \& Garcia-Ochoa, E. (2008). DFT and Electrochemical studies of tris(benzimidazole-2-ylmethyl) amine as an efficient corrosion inhibitor for carbon steel surface. Corrosion Science, 50, 614-624. http://dx.doi.org/10.1016/j.corsci.2007.11.012

Tullock, C. (1999). Stabilization of aluminium and zinc pigments by the addition of chromates. AM. Paints and Coats Journal, 75(49), p.36.

Xia, S., Qui, M., Yu, L. Liu, F., \& Zhao, H. (2008). Molecular dynamics and density functional theory study on relationship between imidazoline derivative and inhibition performance. Corrosion Science, 50, 2021-2029. http://dx.doi.org/10.1016/j.corsci.2008.04.021

Zhang, J., Zhang, Q., Ren, H., Zhao, W., \& Zhang, H. (2007). Inhibition performance of 2-mercaptobenzothiazole derivatives in $\mathrm{CO} 2$ saturated solution and its adsorption behavior at Fe surface. Appl. Surface Science, 253, 7416-7422. http://dx.doi.org/10.1016/j.apsusc.2007.03.035

Zhao, Y. L. P., Liang, Q., \& Hou, B. (2005). Berberine as a natural source inhibitor for mild steel in $1 \mathrm{M} \mathrm{H}_{2} \mathrm{SO}_{4}$ Appl. Surf. Sci., 252, 1245-1253. http://dx.doi.org/10.1016/j.apsusc.2005.02.094 